\title{
Unraveling Pharmacokinetics and Pharmacodynamics in Infants and Children
}

\author{
Anita Sumpter $\cdot$ Brian J. Anderson
}

Published online: 12 December 2012

(C) Springer Science + Business Media New York 2012

\begin{abstract}
Our knowledge of the pharmacology of the drugs used in pediatric anesthesia has advanced with a greater understanding of their pharmacokinetics (PK) and pharmacodynamics. This has resulted in a refinement of their uses, broader indications, and alternative methods of delivery. For example, methadone is becoming increasingly popular for spinal surgery, the dosing of etomidate has been clarified and the PK of intravenous acetaminophen from neonates to adults has been revealed. Morphine PK have also been clarified, although pharmacodynamic ethnic differences remain unexplained. The optimal size descriptor to predict correct drug doses in the obese remains controversial. Efforts to reduce adverse effects of individual drugs have spawned investigations into beneficial drug interactions, although combinations such as propofol and ketamine await PK and safety review. The nasal route may be a reasonable alternative to intravenous administration for many drugs. Oral ketamine may serve as a valuable premedication for children suffering burns. Expanded indications can have unfavorable consequences; propofol may cause profound hypotension in neonates.
\end{abstract}

Keywords Anesthesia - Paediatrics · Pharmacokinetics · Pharmacodynamics · Allometry · Obesity ·

Circadian rhythms

\footnotetext{
A. Sumpter

Departments of Anaesthesia, Auckland Children's Hospital, Park Road, Auckland 1023, New Zealand

e-mail: anitasumpter@adhb.govt.nz

B. J. Anderson ( $\square)$

Department of Anaesthesiology, University of Auckland School of Medicine, Park Road, Auckland 1023, New Zealand

e-mail: briana@adhb.govt.nz
}

\section{Introduction}

Aspects of pharmacology and how these relate to clinical practice remain major areas targeted for future investigation in pediatric anesthesia [1]. The prohibitive cost of developing and bringing new drugs to the market has been partially offset by further exploration of older familiar drugs; refining their use, indications, method of delivery, and interactions with other drugs.

The holy grail of clinical pharmacology is predicting the pharmacokinetics (PK) and pharmacodynamics (PD) of drugs in the individual patient [2]. This requires knowledge of the covariate effects that contribute to variability. Pharmacology is not simply an application of PK, and determinants of drug dose also require an understanding of the variability associated with pharmacodynamic response and a balancing of beneficial effects against unwanted effects [3]. Identification of pharmacodynamic covariates can only benefit children under our care.

\section{New Insights into Old Drugs}

Pediatric anesthesiologists have embraced the population approach for determining drug PK and PD [4]. This approach, achieved through nonlinear mixed effects models, provides a means to study variability in drug responses among individuals representative of those in whom the drug will be used clinically. Allometric scaling using an exponent of 0.75 has proved useful to compare the clearance in adults with those in children older than 2 years [5]. The supplemental use of a maturation model (e.g., a sigmoid maturation function based on postmenstrual age) to describe developmental aspects of clearance in children younger than 2 years allows improved dosing estimates [6]. 
Morphine

Morphine is widely used throughout the human life span, and numerous pharmacokinetic models have attempted to predict the changes in morphine clearance with weight and age. These models have been evaluated using a large external data set to evaluate their ability to predict morphine dose in preterm and full-term neonates, infants, children, and adults. An allometric model using weight combined with a sigmoid maturation model using postmenstrual age successfully predicted the morphine dose rate within $25 \%$ of target in all age groups except infants, where the predicted dose was $30 \%$ under target. Other published models all made unacceptable predictions ( $>100 \%$ of target) in at least one age group. These data further support the theory that allometric scaling combined with a maturation function provides a sound basis for describing clearance and predicting morphine doses in humans of all ages [7••].

\section{Thiopentone}

Thiopentone is an old drug used in children of all ages. Although its use is disappearing, some still prefer this drug over propofol for neonatal intubation because it causes less peripheral vasodilation, and therefore less hypotension, in this age group [8•]. Reported pharmacokinetic parameter estimates have been derived from infusions administered for seizure control in neonates suffering hypoxic-ischaemic insults. While most clearance estimates are less than those in adults $(200 \mathrm{~mL} / \mathrm{h} / \mathrm{kg})$ [9], interpretation is difficult because the hypoxic-ischaemic insult will also affect its clearance. Clearance is through oxidation (CYP2C19) to an inactive metabolite, thiopentone carboxylic acid. Immature hepatic enzymes in neonates decrease the oxidising capacity. CYP2C19 microsomal activity is approximately $30 \%$ of mature values in the third trimester, but increases dramatically at birth [10]. A recent analysis of the maturation of thiopentone clearance using an allometric model with weight and a maturation model with PMA yielded results consistent with the maturation of CYP2C19. Clearance rapidly increases during the neonatal period from $33 \mathrm{~mL} / \mathrm{h} / \mathrm{kg}$ at 24 weeks postmenstrual age to $160 \mathrm{~mL} / \mathrm{h} / \mathrm{kg}$ at term [11•]. Neonates have less fat and muscle mass than adults and this is reflected in their reduced peripheral volume of distribution [11•]. A smaller clearance and peripheral volume of distribution means that plasma concentrations remain increased in neonates when compared with adults for a given dose. This is reflected in reduced dose requirements for neonates; the $\mathrm{ED}_{50}$ of thiopentone is $3.4 \mathrm{mg} / \mathrm{kg}$ in neonates and $4.1 \mathrm{mg} / \mathrm{kg}$ in adolescents aged 12-16 years [12, 13].
Etomidate

Etomidate is another old drug that continues to be used in children despite a lack of approval and a paucity of pharmacokinetic information. Pharmacokinetics have now been characterised in children ( $n=49,6$ months-13 years) using an allometric model based on weight [14•]. The authors report an increased clearance and an increased central compartment volume of etomidate compared with adults. Consequently, younger children require a greater per-kilogram induction dose of etomidate compared with older children to achieve equivalent plasma concentrations [14•]. However, the use of etomidate has been plagued by concerns about adrenal suppression. These concerns have led to the development of a new compound, methoxycarbonyl-carboetomidate, which has a very rapid offset because of esterase hydrolysis, as well as virtually no adrenal suppression, while maintaining the potency of the parent compound [15]. This compound offers real promise and could offer an alternative to propofol for short term sedation.

\section{Methadone}

Intravenous methadone may be administered to pediatric patients undergoing posterior spinal fusion [16] and major abdominal surgery [17]. Methadone's long duration of action and $N$-Methyl-D-aspartate (NMDA) receptor antagonism are perceived as advantages for children who may experience prolonged pain. Methadone is cleared predominantly by the hepatic $\mathrm{P} 450$ cytochrome enzymes CYP2B6 and CYP3A4, and to a lesser extent by CYP2C19 [18]. These hepatic enzyme systems mature rapidly within the first few years of postnatal life [19], and we might expect the PK after infancy to be similar to those described in young adults, if scaled using allometry [6]. However, the optimal dosing regimen for methadone remains uncertain because of sparse pharmacokinetic data in children and a paucity of analgesic effect data. It has been suggested that the analgesic $\mathrm{EC}_{50}$ is $58 \mathrm{mcg} / \mathrm{L}$ in the opioid-naïve adult [20], but comparable data in children are lacking, and whether these concentrations are achieved at the conclusion of spinal surgery is unknown. Recently, Sharma [21•] reported the $\mathrm{PK}$ of methadone in adolescents, however they presented a non-compartmental isomer analysis, making direct comparison to reported adult values awkward. Another compartmental analysis of the methadone racemate commonly used revealed that PK parameter estimates in adolescents are indeed similar to those reported in adults when scaled using allometry [22•]. Methadone undergoes rapid redistribution after bolus administration. This may result in plasma concentrations that provide inadequate analgesia postoperatively if the drug is given at the start of 
anesthesia. The authors suggested that an infusion $(0.1-0.15 \mathrm{mg} / \mathrm{kg} / \mathrm{h})$ be used during spinal surgery to ensure adequate plasma concentrations for $24 \mathrm{~h}$. Alternatively, subsequent dosing based upon pain severity (i.e., $0.03 \mathrm{mg}$ / $\mathrm{kg}$ for mild pain and $0.05 \mathrm{mg} / \mathrm{kg}$ for severe pain) every $4 \mathrm{~h}$ may provide sustained analgesia after bolus redistribution. Caution has been expressed against administering a large second bolus immediately after surgery because the concentration-response relationship for sedation and respiratory depression in opioid naïve children has not been elucidated [22•].

\section{Nonsteroidal Anti-inflammatory Drugs (NSAIDs)}

Conflicting reports plague the literature in terms of the relative analgesic efficacy of NSAIDs and acetaminophen, when administered individually. An early meta-analysis that compared single doses of acetaminophen, 7-15 mg/kg, with ibuprofen $4-10 \mathrm{mg} / \mathrm{kg}$, reported similar analgesic effects in children [23]. However, a more recent meta-analysis concluded that ibuprofen was at least as effective, if not more than acetaminophen in both adults and children [24]. These conflicting results have been clarified by data from adults who were given ibuprofen after dental extraction. The maximum analgesic effect (1.54 of a scale 0-3) [25] was similar to that described for acetaminophen (5.3 of a scale $0-10)$ [26]. Importantly, the equilibration half-time $\left(T_{1 / 2} \mathrm{keo}\right)$ of $28 \mathrm{~min}$ for ibuprofen was less than the $53 \mathrm{~min}$ reported for acetaminophen [26] and the slope of the concentrationresponse curve was steeper than that for acetaminophen. These data indicate that although these two NSAIDs may be equally efficacious, the onset of analgesia with ibuprofen is more rapid than that with acetaminophen.

NSAIDs reduce opioid consumption and the incidence of postoperative vomiting during in children [27•]. The effective dose of diclofenac has been estimated based on the assumption that attaining similar adult exposure to $50 \mathrm{mg}$ in children should give similar effectiveness. This argument has been used to support a single dose of diclofenac $0.3 \mathrm{mg} / \mathrm{kg}$ for intravenous administration, $0.5 \mathrm{mg} /$ $\mathrm{kg}$ for suppositories, and $1 \mathrm{mg} / \mathrm{kg}$ for oral diclofenac in children aged $1-12$ years [28••].

Interpretation of analgesia is also complicated by the effects of active metabolites. Diclofenac has a 4'-hydroxyl metabolite that contributes $30 \%$ of the anti-inflammatory and antipyretic activity of the parent compound. The effect of parecoxib, a cyclooxygenase- 2 selective inhibitor, is entirely through its active metabolite valdecoxib. These PK in children have been elucidated. The clearance of valdecoxib matures with a maturation half-time of 87 weeks PMA [29•], which is similar to that described for midazolam; a drug that is also cleared by primarily CYP3A4 with some contribution from CYP2C9 [30]. The authors used a similar approach to dosing as that used for diclofenac [28*0]. In order to achieve equivalent adult exposure to $40 \mathrm{mg} \mathrm{IV}$, children (2-13 years) should be given $0.9 \mathrm{mg} / \mathrm{kg}$ IV if they weigh $10-14 \mathrm{~kg}, 0.8 \mathrm{mg} / \mathrm{kg}$ IV if $15-24 \mathrm{~kg}$, $0.7 \mathrm{mg} / \mathrm{kg}$ IV if $24-39 \mathrm{~kg}$ and $0.6 \mathrm{mg} / \mathrm{kg}$ IV if $40-69 \mathrm{~kg}$. These doses reflect the elimination clearance of parecoxib, which was scaled using allometry in children ages $1.1-12.7$ years [29•]. The simulated free valdecoxib concentration exceeded the in vitro $50 \%$ inhibitory concentration for free valdecoxib for at least $12 \mathrm{~h} \mathrm{[29 \bullet ].}$

\section{Ketamine}

There has been a resurgence in the use of ketamine $(0.5-1 \mathrm{mg} / \mathrm{kg})$ for procedures of brief duration in the emergency room [31•*]. A case-control analysis of the largest available sample of ketamine-associated laryngospasm in the emergency room $(n=8,282)$ did not demonstrate evidence of association with age, dose, or other clinical factors. Laryngospasm appeared to be idiosyncratic [32]. This report is consistent with rat data that suggests ketamine is a respiratory stimulant that abolishes the coupling between loss-of-consciousness and upper airway dilator muscle dysfunction over a wide dose-range [33]. Adverse respiratory events are associated with large intravenous doses, administration to children younger than 2 years or aged 13 years or older, and the use of coadministered anticholinergics or benzodiazepines [34].

'Ketofol' is a mixture of ketamine and propofol (1:1) that is finding a niche for procedural sedation in the emergency room. Stable hemodynamics, analgesia and good recovery are reported [35॰]. This mixture is creeping into anesthetic practice, although the ideal mixture remains unknown. It is probable that the 'ideal mix' will depend on the duration of sedation required. The context sensitive half-times for propofol and ketamine increase with the duration of the infusion [36]. The limited number of prospective studies at this time precludes an assessment of safety and efficacy of this combination.

\section{Acetaminophen}

The release of an intravenous formulation of acetaminophen in the USA has increased interest in this drug. A population analysis [37] using allometry and a maturation model has confirmed earlier parameter estimates determined using propacetamol (an intravenous prodrug of acetaminophen) in children [38]. Intravenous acetaminophen in infants, children, and adolescents was well tolerated and achieved plasma concentrations similar to those achieved with labelled $15 \mathrm{mg} / \mathrm{kg}$ body weight doses by oral or rectal administration. In Europe, the PK of acetaminophen in neonates have been further explored. Weight was 
used to predict patient size and was the major covariate contributing $57.5 \%$ of variance. Clearance expressed as $\mathrm{mg} / \mathrm{kg} / \mathrm{h}$ increases only slightly with PMA $(0.138 \mathrm{~L} / \mathrm{kg} / \mathrm{h}$ at 28 weeks' PMA to $0.167 \mathrm{~L} / \mathrm{kg} / \mathrm{h}$ at 44 weeks' PMA). Using these estimates, a mean acetaminophen serum concentration of $11 \mathrm{mg} / \mathrm{L}$ is predicted in neonates of 32-44 weeks' PMA given a standard dose of intravenous acetaminophen of $10 \mathrm{mg} / \mathrm{kg}$ every $6 \mathrm{~h} \mathrm{[39 \bullet ].} \mathrm{Safety} \mathrm{data}$ for this drug are limited in neonates and surveillance therefore remains essential. Tenfold dosing errors have occurred in paediatric practice and this error has been reported in neonates given IV acetaminophen [40].

Future acetaminophen analyses may be simplified in part, through the use of 'blood spot' sampling. As little as $30 \mathrm{mcL}$ of blood is spotted on to a Guthrie card, ensuring that the blood soaks through to the other side of the card and then allowed to dry at room temperature overnight in darkness. Blood spots are stored in sealed airtight plastic bags at $48{ }^{\circ} \mathrm{C}$ in a secured fridge until chromatographic analysis [41, 42].

\section{The Growing Obesity Issue}

\section{A Scaler for Dosing}

Children presenting for adenotonsillectomy have a greater incidence of perioperative complications and are more likely to be admitted and/or remain in hospital for prolonged periods compared with their normal-weight peers $[43,44]$. While simple measures such as neck circumference may warn practitioners of the increased incidence of postoperative respiratory complications [45], a suitable index relating dose to body mass remains elusive.

Pharmacokinetic properties of some drugs are known to change in obesity [46]. Although body fat has minimal metabolic activity, fat mass contributes to overall body size and may have an indirect influence on both metabolic and renal clearance. On the other hand, the volume of distribution of a drug depends on its physicochemical properties [47]. The apparent volume of distribution of some drugs may be independent of fat mass (e.g., digoxin), whereas others are extensively determined by it (e.g., diazepam). To address the pharmacokinetic differences among drugs in obese patients, several size descriptors have been proposed for use in these patients including total body weight (TBW), lean body weight (LBW), ideal body weight (IBW), body mass index (BMI), fat free mass (FFM), normal fat mass (NFM).

One controversial issue is the selection of the optimal size descriptor to scale pharmacokinetic parameters when adjusting the dose of propofol for the obese patient [48, 49]. In normal-weight subjects, total body weight is a good size descriptor and a good approximation of lean body mass [48]. However, in obese patients, total body weight

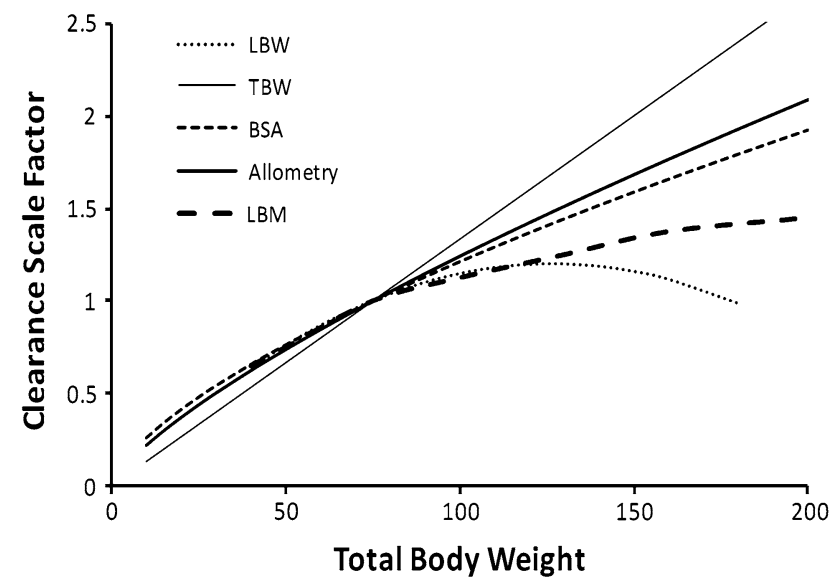

Fig. 1 Size descriptors used to scale clearance. Scaling factors are based on a median population TBW of $75 \mathrm{~kg}$ and height of $180 \mathrm{~cm}$. A nonlinear relationship exists between weight and clearance and the use of TBW overestimates clearance. The other descriptors are in close agreement between 45 and $100 \mathrm{~kg}$. The classic formula for lean body weight (LBW [52]) fails at weights greater than $120 \mathrm{~kg}$. The use of body surface area (BSA) and allometry using an exponent of 0.75 are similar and diverge from lean body mass (LBM [53]) over weights of $100 \mathrm{~kg}$. The correct descriptor probably differs for each drug and will lie between the allometric and LBM curves. The relationship in children remains relatively unexplored

overestimates lean body mass because the increase in lean body mass only represents $20-40 \%$ of total excess weight [46, 49-51]. As a result, the optimal size descriptor that provides the most accurate information about the relationship between propofol dose and its plasma concentrations remains unclear (Fig. 1) [49].

\section{Propofol}

The effective dose of propofol for loss of lash reflex in obese pediatric patients $\left(\mathrm{ED}_{95} 2.0 \mathrm{mg} / \mathrm{kg}, 95 \% \mathrm{CI}\right.$ $1.8-2.2 \mathrm{mg} / \mathrm{kg}$ ) is less than that in their non-obese counterparts $(3.2 \mathrm{mg} / \mathrm{kg}, 95 \%$ CI $2.7-3.2 \mathrm{mg} / \mathrm{kg})$. Obese children (BMI $>95$ th percentile for age and gender) require a reduced weight-based dose of propofol for induction of anesthesia when compared with normal-weight children [54]. This has been attributed to the nonlinear relationship between weight and clearance. Although lean body weight has been proposed as the ideal measure for propofol [55, 56], allometric scaling using total body weight with an exponent of 0.75 may be more appropriate $[6,57]$. This same exponent has been advocated for the clearance of propofol in obese adults [58] and children [59] although a recent analysis suggested an exponent of 0.8 in obese children may be superior [60॰]. We find it difficult to accept claims that the allometric coefficient differs from 0.75 based on an estimation from almost any realistic study design. The exponents $0.66,0.75$ and 0.85 , for example, provide the same degree of accuracy or error in the 
prediction of clearance in children [6]. There is a real danger estimating the allometric exponent using a narrow range of children's weights. Investigators who focus only on obese subjects rather than a broad weight range that included normal-weight subjects, may not find a realistic allometric relationship [58]. Strange reports of negative exponents that imply clearance decreases with weight have been published [61].

Another danger is attempting to use the 'one size descriptor fits all' approach to all drugs [62]. An allometric model using TBW may be appropriate for propofol, a drug with high fat solubility. However, this approach may be inappropriate for remifentanil, as lean body weight is a better size descriptor [63]. Hence, the size descriptor may differ for each drug. The use of normal fat mass with allometric scaling as a size descriptor may prove versatile [64]. That size descriptor uses the idea of fat fee mass (similar to LBW but excludes lipids in cell membranes, CNS and bone marrow) plus a 'bit more'. The 'bit more' will differ for each drug and the maximum 'bit more' added to fat free mass would equal TBW.

\section{Alternative Delivery Routes}

Exploration of alternative delivery routes for drugs in young children has centred on the nasal passages. Buccal and sublingual administration in children is unsatisfactory because they require prolonged exposure to the mucosal surface. Younger children find it difficult to comply with instructions to hold drugs in their mouths for the requisite retention time (particularly if the taste is unfavorable), and this results in more drug swallowed or expectorated than in adults. If the drug has a large first-pass effect then the reduced relative bioavailability decreases the plasma concentrations.

In contrast, the nasal route for opioid delivery is gaining popularity in children [65••]. Nasal diamorphine, $0.1 \mathrm{mg} / \mathrm{kg}$, is used in the UK for forearm fracture pain in the emergency room [66-69], but for the remainder of the world, fentanyl remains the stalwart. Nasal fentanyl $(150 \mathrm{mcg} / \mathrm{mL}) 1.5 \mathrm{mcg} / \mathrm{kg}$ given to children (3-17 years) with fracture pain resulted in good analgesia. The pain score (VAS 0-100) decreased from $80 \mathrm{~mm}$ (IQR 60.0-95.5) to $49.5 \mathrm{~mm}$ (IQR 26.5-68.5) by $10 \mathrm{~min}$ and to $27.5 \mathrm{~mm}$ (IQR 18.5-56.5) by $20 \mathrm{~min}$ after administration $[70,71 \bullet$. Similar results have been reported for fentanyl $(4 \mathrm{mcg} / \mathrm{kg})$ administered through a standard nebulizer [72]. Studies in adults using a pectin-based gelling agent that modulates fentanyl absorption while limiting nasal drip or runoff hold promise and have proven useful in controlling breakthrough pain in adult cancer patients [73]. However, there remain few studies investigating the usefulness of intraoperative nasal fentanyl in children. It might be used in anesthesia where intravenous access is not always secured (e.g., myringotomy and ventilation tube placement). However, opioids are uncommonly required for such procedures and there remain concerns that intranasal drugs may pass through the posterior nasopharynx and irritate the vocal cords or through the cribriform plate and cause neurotoxicity [74•].

Advances in aerosol delivery devices have improved dosing accuracy. Administration of ketorolac $15 \mathrm{mg}$ (weight $<50 \mathrm{~kg}$ ) or $30 \mathrm{mg}$ (weight $>50 \mathrm{~kg}$ ) by the intranasal route resulted in a rapid increase in plasma concentration (time to peak (mean $\pm \mathrm{SD}$ ) concentration was $52 \pm 6 \mathrm{~min}$ ) and may be a useful therapeutic alternative to IV injection in adolescents because plasma concentrations attained with the device are likely to be analgesic. A target concentration of $0.37 \mathrm{mg} / \mathrm{L}$ in the effect compartment was achieved within $30 \mathrm{~min}$ and remained above that target for $10 \mathrm{~h}\left[75^{\bullet}\right]$. It is somewhat concerning that these nasal doses are inconsistent with an adult meta-analysis that demonstrated that a single dose of systemic ketorolac is an effective adjunct in multimodal regimens to reduce postoperative pain and reduce postoperative nausea and vomiting. The $60-\mathrm{mg}$ dose offered benefits, but there was a lack of current evidence that the 30-mg dose offered significant benefits on postoperative pain outcomes [76 ]. The nasal dose may require revision.

Clonidine administered as a nasal aerosol $(3-8 \mathrm{mcg} / \mathrm{kg})$ did not achieve adequate preoperative sedation within 30 min of administration. Despite its sedative properties, postoperative sedation was not prolonged compared with placebo [77]. The oral bioavailability of clonidine is also poor $(F=0.55)$ in children 3-10 years. Consequently, larger oral doses (per $\mathrm{kg}$ ) are required when this formulation is used to achieve concentrations similar to those reported in adults [78].

Similarly, oral ketamine needs to be given in doses of up to $10 \mathrm{mg} / \mathrm{kg}$ to achieve therapeutic effects in children 1-8 years with burns [79•]. This contrasts with a dose of $4-6 \mathrm{mg} / \mathrm{kg}$ oral ketamine for premedication in healthy children. These differing dose requirements may be explained by differences in the absorption characteristics of children with burns. Not only was bioavailability reduced $(F=0.45)$ but absorption was also slow; absorption halftime was $59 \mathrm{~min}$ and inter-subject variability was large in this cohort. Dose simulation in a burned child (3.5 years, $15 \mathrm{~kg}$ ) suggested a dosing regimen of oral ketamine, $10 \mathrm{mg} / \mathrm{kg}$, followed by intravenous ketamine, $1 \mathrm{mg} / \mathrm{kg}$ at 45 min for a brief surgical dressing change [79•].

\section{Drug Interactions}

Acetaminophen-Ibuprofen

Acetaminophen and NSAIDs can be safely combined without increasing their associated adverse-effect profiles. 
As a result, combination therapy has become very popular. A review of randomized controlled studies identified six studies that compared combined acetaminophen and ibuprofen therapy for postoperative pain [80]. Of these, three were conducted in pediatric populations: oral premedication with the combination was superior to acetaminophen alone for pain after tonsillectomy in children and after tooth extraction, while rectal administration of the combination did not differ from acetaminophen alone for pain after adenoidectomy. However, in the latter study, the need for rescue analgesia was reduced in the combination group at home.

These disparate results may be explained as follows. Dose-response curves for the combination therapy in adults suffering dental pain have been published [81]. Analysis of those data using a response surface area allowed dose interpretation in children [82•]. Simulation for a $20-\mathrm{kg}$ child showed that the addition of acetaminophen to ibuprofen in doses less than $5 \mathrm{mg} / \mathrm{kg}$ reduced the pain response, whereas acetaminophen added to ibuprofen in doses greater than $5 \mathrm{mg} / \mathrm{kg}$ had minimal effect in the immediate postoperative period. A more sustained analgesic effect was noted at 4-8 $\mathrm{h}$ after combination therapy. Combination therapy achieves effective analgesia with a reduced daily dose of acetaminophen (e.g., $60 \mathrm{mg} / \mathrm{kg} /$ day), and therefore reduced concern of hepatotoxicity. Unfortunately, combination therapy does not provide prolonged analgesia sufficient to maintain adequate analgesia overnight [83].

\section{Ketamine-Phenobarbital}

Drug interactions may also be the consequence of prolonged therapy. Phenobarbital, used for seizure control, induces CYP3A4 [84], an enzyme responsible for ketamine clearance. Ketamine, which is metabolized by CYP3A4, has a reduced sedative effect in children who are receiving long-term phenobarbital therapy $[85,86]$.

\section{Combination Therapy for Tracheal Intubation Without Neuromuscular Blocking Drugs}

Although succinylcholine is considered the golden standard for optimizing intubating conditions, tracheal intubation without prior administration of muscle relaxants is common. A systematic review identified several drug combinations for induction of anesthesia with sevoflurane or propofol in children aged 1-9 years. One combination used sevoflurane and propofol $(3 \mathrm{mg} / \mathrm{kg}$ ) without premedication, and spontaneous breathing showed that propofol may be the adjuvant of choice for a rapid sevoflurane induction. The only adjuvant identified during a propofol induction was IV remifentanil (4 mcg/kg) [87•].

\section{Pharmacodynamic Considerations}

Anesthesia Monitoring

Bispectral monitoring (BIS) has become acceptable in adults as a measure of anesthesia depth. However, there remains a need for specific neonate-derived algorithms if EEG-derived anesthesia depth monitors are to be used in neonates. Problems with BIS monitoring in young children include a paradoxical increase when the sevoflurane concentrations exceed $3 \%$, differences between the right and left side of the brain, discrepant BIS values among inhalational agents at equivalent MAC values, and BIS values in children that exceeded those in adults at equivalent MAC values [88]. An explanation for the last finding is that brain structure sensitivities differ with brain maturation [89]. Data also suggest that the spectral entropy for deep sedation and surgical anesthesia in children 3-6 years exceed those in children 6-16 years during propofol-remifentanyl infusion [90]. However, these results are also consistent with dose scaling based on allometry. Because clearance is increased in children, younger children have lower drug concentrations when the same infusion (per kilogram) is administered in all ages, as was the case in that study.

\section{Pharmacodynamic Covariates}

Considerable strides have been made identifying pharmacodynamic covariates. Bradycardia during anesthetic induction with sevoflurane was common in children with Down syndrome [91]. Critical illness is a major determinant for the clearance of midazolam [92•]. Opioid administration was reduced in otherwise healthy children with altitude-induced chronic hypoxia when compared with non-hypoxic children undergoing similar operations under similar anesthetic regimens [93]. Opioid dose also appears to vary geographically; that is, children in Central and South America receive less opioid intraoperatively than do children in Africa and India, under standardized anesthesia for cleft surgeries [94•]. Ethnicity may contribute to this observation. There were differences in the occurrence of adverse effects after morphine administration between Latino and non-Latino Caucasian children. Neither differences in morphine or metabolite concentrations, nor the genetic polymorphisms examined, explained these findings [95•].

The management of postoperative pain can only improve with greater understanding of its severity and duration. Children experience significant pain and severe functional limitation up to 7 days after tonsillectomy or orchidopexy; effects that may persist into the second postoperative week [96]. Substantial pain persists on day 2 
even after laparoscopic appendicectomy [97]. Children with intellectual disability (e.g., Trisomy 21 ) suffer postoperative pain to a similar effect as unaffected children, leading many to advocate similar perioperative analgesia care for the two groups $[98,99 \bullet]$.

\section{"Jet lag" After Anesthesia}

Children often experience sleep disturbance after anesthesia. Part of this effect may be attributed to disruption of the internal circadian clock. The honey bee has a circadian clock that is similar to that found in humans. After a $6 \mathrm{~h}$ anaesthetic, bees showed a delay in the start of foraging and whole-hive locomotor-activity rhythms that were delayed by an average of $4.3 \mathrm{~h}$. Messenger RNA of circadian clock genes was altered by anesthetic exposure, suggesting that general anesthesia alters the circadian clock in a manner consistent with jet lag [100••].

\section{Conclusion}

Our knowledge of pediatric pharmacology as it pertains to the anesthesiologist continues to expand. However, translation of this knowledge into practical anesthesia has been haphazard and incomplete. By investigating the complex PK of a drug, interactions between drugs, and the pharmacodynamic effects of these findings in different subpopulations of infants and children, we can identify the key covariates that will enable clinicians to prescribe effective doses of drugs while limiting the adverse effects in the individual child.

Acknowledgments A. Sumpter is supported by ANZCA Grant No 08-011.

Disclosure A. Sumpter: none; B.J. Anderson has served as a consultant for McNeil Pharmaceuticals and was reimbursed by AFT Pharmaceuticals for travel/accommodations/meeting expenses.

\section{References}

Papers of particular interest, published recently, have been highlighted as:

- Of importance

•- Of major importance

1. Davidson AJ. In search of the big question. Pediatr Anesth. 2012;22(7):613-5.

2. Benet LZ. A Holy Grail of clinical pharmacology: prediction of drug pharmacokinetics and pharmacodynamics in the individual patient. Clin Pharmacol Ther. 2009;86(2):133-4.
3. Anderson BJ. My child is unique; the pharmacokinetics are universal. Pediatr Anesth. 2012;22(6):530-8.

4. Thomson AH, Elliott HL. Designing simple PK-PD studies in children. Paediatr Anaesth. 2011;21(3):190-6.

5. Anderson BJ, Holford NH. Tips and traps analyzing pediatric PK data. Paediatr Anaesth. 2011;21(3):222-37.

6. Anderson BJ, Holford NH. Mechanistic basis of using body size and maturation to predict clearance in humans. Drug Metab Pharmacokinet. 2009;24(1):25-36.

7. $\bullet$ Holford NH, Ma SC, Anderson BJ. Prediction of morphine dose in humans. Pediatr Anesth. 2012;22(3):209-22. Argument exists about the best model to describe clearance and its changes from premature neonate to adult. These authors used an external data set to evaluate published models for morphine clearance. Clearance based on empirical allometric scaling predicted unacceptable doses. Theory-based allometric scaling combined with a maturation function provided a sound basis for describing clearance and predicting morphine doses in humans of all ages.

8. - Lerman J, Heard C, Steward DJ. Neonatal tracheal intubation: an imbroglio unresolved. Pediatr Anesth. 2010;20(7):585-90. This editorial highlights the dangers of using drugs in patient groups who have not been exposed to rigorous investigation. The lesson learnt from bupivacaine induced seizures in neonates is again ignored. Propofol can cause profound hypotension in neonates.

9. Stanski DR, Maitre PO. Population pharmacokinetics and pharmacodynamics of thiopental: the effect of age revisited. Anesthesiology. 1990;72(3):412-22.

10. Koukouritaki SB, Manro JR, Marsh SA, et al. Developmental expression of human hepatic CYP2C9 and CYP2C19. J Pharmacol Exp Ther. 2004;308(3):965-74.

11. - Larsson P, Anderson BJ, Norman E, Westrin P, Fellman V. Thiopentone elimination in newborn infants: exploring Michaelis-Menten kinetics. Acta Anaesthesiologica Scandinavica. 2011;55(4):444-51. It seems strange that a drug that is now disappearing from common use is finally investigated in order to understand its $P K$ in neonates. While it is no surprise that clearance is reduced and increases with age, characterization of $P K$ changes with age allows greater understanding of this drug.

12. Westrin P, Jonmarker C, Werner O. Thiopental requirements for induction of anesthesia in neonates and in infants one to six months of age. Anesthesiology. 1989;71(3):344-6.

13. Jonmarker C, Westrin P, Larsson S, Werner O. Thiopental requirements for induction of anesthesia in children. Anesthesiology. 1987;67(1):104-7.

14. • Lin L, Zhang JW, Huang Y, Bai J, Cai MH, Zhang MZ. Population pharmacokinetics of intravenous bolus etomidate in children over 6 months of age. Pediatr Anesth. 2012;22(4): 318-26. Characterization of $P K$ in children allows improved dosing. Children have greater clearance and central compartment volume; younger children require a larger etomidate bolus dose than older children to achieve equivalent plasma concentrations.

15. Pejo E, Cotten JF, Kelly EW, et al. In vivo and in vitro pharmacological studies of methoxycarbonyl-carboetomidate. Anesth Analg. 2012;115(2):297-304.

16. Gottschalk A, Durieux ME, Nemergut EC. Intraoperative methadone improves postoperative pain control in patients undergoing complex spine surgery. Anesth Analg. 2011;112(1): 218-23.

17. Berde CB, Beyer JE, Bournaki MC, Levin CR, Sethna NF. Comparison of morphine and methadone for prevention of postoperative pain in 3- to 7-year-old children. J Pediatr. 1991;119(1 (Pt 1)):136-41. 
18. Kharasch ED, Hoffer C, Whittington D, Sheffels P. Role of hepatic and intestinal cytochrome P450 3A and 2B6 in the metabolism, disposition, and miotic effects of methadone. Clin Pharmacol Ther. 2004;76(3):250-69.

19. Kearns GL, Abdel-Rahman SM, Alander SW, Blowey DL, Leeder JS, Kauffman RE. Developmental pharmacology_drug disposition, action, and therapy in infants and children. N Engl J Med. 2003;349(12):1157-67.

20. Gourlay GK, Willis RJ, Wilson PR. Postoperative pain control with methadone: influence of supplementary methadone doses and blood concentration-response relationships. Anesthesiology. 1984;61(1):19-26.

21. - Sharma A, Tallchief D, Blood J, Kim T, London A, Kharasch ED. Perioperative pharmacokinetics of methadone in adolescents. Anesthesiology. 2011;115(6):1153-61. Methadone is gaining increased therapeutic use for pain in children. These investigators performed a non-compartmental analysis to characterize methadone enantiomer disposition in adolescents undergoing surgery and shown that they are to those in healthy adults.

22. - Stemland CJ, Witte J, Colquhoun DA, et al. The pharmacokinetics of methadone in adolescents undergoing posterior spinal fusion. Pediatr Anesth. 2013;23:51-7. Anesthesiologists like compartmental analyses because they allow prediction of timeconcentration profiles. This practical paper examines methadone using a 3-compartment model for racemic methadone. It complements that of Ref. [21 $\bullet \bullet]$ and suggests dosing regimens that might achieve a target concentration during and after scoliosis surgery.

23. Perrott DA, Piira T, Goodenough B, Champion GD. Efficacy and safety of acetaminophen vs ibuprofen for treating children's pain or fever: a meta-analysis. Arch Pediatr Adolesc Med. 2004;158(6):521-6.

24. Pierce CA, Voss B. Efficacy and safety of ibuprofen and acetaminophen in children and adults: a meta-analysis and qualitative review. Ann Pharmacother. 2010;44(3):489-506.

25. Li H, Mandema J, Wada R, et al. Modeling the onset and offset of dental pain relief by ibuprofen. J Clin Pharmacol. 2012;52(1): 89-101.

26. Anderson BJ, Woollard GA, Holford NH. Acetaminophen analgesia in children: placebo effect and pain resolution after tonsillectomy. Eur J Clin Pharmacol. 2001;57(8):559-69.

27. - Michelet D, Andreu-Gallien J, Bensalah T, et al. A metaanalysis of the use of nonsteroidal antiinflammatory drugs for pediatric postoperative pain. Anesth Analg. 2012;114(2): 393-406. The opioid-sparing effectof NSAIDs is still controversial. The authors reviewed 27 randomized control trials to show that that perioperative NSAID administration reduces opioid consumption and PONV during the postoperative period in children.

28. • Standing JF, Tibboel D, Korpela R, Olkkola KT. Diclofenac pharmacokinetic meta-analysis and dose recommendations for surgical pain in children aged 1-12 years. Pediatr Anesth. 2011;21(3):316-24. Diclofenac dosing in children remains unknown because there is no concentration response relationship established. These authors performed a PK population analysis using pooled data that included rectal, oral and intravenous formulations. They were able to predict dose in children by estimating the dose that would achieve a similar AUC as adults.

29. - Hullett B, Salman S, O'Halloran SJ, Peirce D, Davies K, Ilett KF. Development of a population pharmacokinetic model for parecoxib and its active metabolite valdecoxib after parenteral parecoxib administration in children. Anesthesiology. 2012;116(5):1124-33. Parecoxib is one of the few NSAIDs available as an intravenous formulation. Use has been hindered by a lack of PK knowledge in children. The drug is a active through its metabolite and the authors suggest doses that achieve a metabolite target concentration.

30. Anderson BJ, Larsson P. A maturation model for midazolam clearance. Paediatr Anaesth. 2011;21(3):302-8.

31. • Green SM, Roback MG, Kennedy RM, Krauss B. Clinical practice guideline for emergency department ketamine dissociative sedation: 2011 update. Ann Emerg Med. 2011;57(5): 449-61. These authors have popularized the use of ketamine in the ED. Guidelines for use are updated with respect to contraindications, age recommendations, potential neurotoxicity, and the role of coadministered anticholinergics and benzodiazepines. They critically discuss indications, contraindications, personnel requirements, monitoring, dosing, coadministered medications, recovery issues, and future research questions.

32. Green SM, Roback MG, Krauss B. Laryngospasm during emergency department ketamine sedation: a case-control study. Pediatr Emerg Care. 2010;26(11):798-802.

33. Eikermann M, Grosse-Sundrup M, Zaremba S, et al. Ketamine activates breathing and abolishes the coupling between loss of consciousness and upper airway dilator muscle dysfunction. Anesthesiology. 2012;116(1):35-46.

34. Green SM, Roback MG, Krauss B, et al. Predictors of airway and respiratory adverse events with ketamine sedation in the emergency department: an individual-patient data meta-analysis of 8,282 children. Ann Emerg Med. 2009;54(2):158-68 e1-4.

35. - Andolfatto G, Abu-Laban RB, Zed PJ, et al. Ketamine-propofol combination (ketofol) versus propofol alone for emergency department procedural sedation and analgesia: a randomized double-blind trial. Ann Emerg Med. 2012;59(6): 504-12 e1-2. Ketamine-propofol combinations are creeping into clinical practice because sedation depth appears to be more consistent with ketofol. Although a reduced incidence of adverse respiratory events compared with propofol alone is reported, data remain few. Drug ratios remain undefined.

36. Dallimore D, Anderson BJ, Short TG, Herd DW. Ketamine anesthesia in children-exploring infusion regimens. Pediatr Anesth. 2008;18(8):708-14.

37. Zuppa AF, Hammer GB, Barrett JS, et al. Safety and population pharmacokinetic analysis of intravenous acetaminophen in neonates, infants, children, and adolescents with pain or Fever. J Pediatr Pharmacol Ther. 2011;16(4):246-61.

38. Anderson BJ, Pons G, Autret-Leca E, Allegaert K, Boccard E. Pediatric intravenous paracetamol (propacetamol) pharmacokinetics: a population analysis. Pediatr Anesth. 2005;15(4): 282-92.

39. - Allegaert K, Palmer GM, Anderson BJ. The pharmacokinetics of intravenous paracetamol in neonates: size matters most. Arch Dis Child. 2011;96(6):575-80. Although intravenous acetaminophen is used in neonates, dose is uncertain because of limited PK knowledge. The authors analysed data from 158 neonates $A$ mean paracetamol serum concentration of $11 \mathrm{mg} / \mathrm{L}$ is predicted in neonates of 32-44 weeks' PMA given a standard dose of intravenous paracetamol of $10 \mathrm{mg} / \mathrm{kg}$ every $6 \mathrm{~h}$. Safety data for this drug are limited in neonates.

40. Beringer RM, Thompson JP, Parry S, Stoddart PA. Intravenous paracetamol overdose: two case reports and a change to national treatment guidelines. Arch Dis Child. 2011;96:307-8.

41. Mohammed BS, Engelhardt T, Cameron GA, et al. Population pharmacokinetics of single-dose intravenous paracetamol in children. Br J Anaesth. 2012;108(5):823-9.

42. Millership JS. Microassay of drugs and modern measurement techniques. Pediatr Anesth. 2011;21(3):197-205.

43. Nafiu OO, Green GE, Walton S, Morris M, Reddy S, Tremper $\mathrm{KK}$. Obesity and risk of peri-operative complications in children presenting for adenotonsillectomy. Int J Pediatr Otorhinolaryngol. 2009;73(1):89-95. 
44. Gleich SJ, Olson MD, Sprung J, et al. Perioperative outcomes of severely obese children undergoing tonsillectomy. Pediatr Anesth. 2012;22(12):1171-8.

45. Nafiu OO, Burke CC, Gupta R, Christensen R, Reynolds PI, Malviya S. Association of neck circumference with perioperative adverse respiratory events in children. Pediatrics. 2011;127(5): e1198-205.

46. Han PY, Duffull SB, Kirkpatrick CM, Green B. Dosing in obesity: a simple solution to a big problem. Clin Pharmacol Ther. 2007;82(5):505-8.

47. Abernethy DR, Greenblatt DJ. Drug disposition in obese humans. An update. Clin Pharmacokinet. 1986;11(3):199-213.

48. Bouillon T, Shafer SL. Does size matter? Anesthesiology. 1998; 89(3):557-60.

49. Green B, Duffull SB. What is the best size descriptor to use for pharmacokinetic studies in the obese? Br J Clin Pharmacol. 2004;58(2):119-33.

50. Casati A, Torri G. Cardiovascular stability during inhalational anaesthesia in morbidly obese patients: which is better, sevoflurane or desflurane? Br J Anaesth. 2004;93(1):153-4. author reply 4-5.

51. Peters AM, Snelling HL, Glass DM, Love S, Bird NJ. Estimated lean body mass is more appropriate than body surface area for scaling glomerular filtration rate and extracellular fluid volume. Nephron Clin Pract. 2010;116(1):c75-80.

52. James W. Research on obesity. In: Her Majesty's Stationary Office. London; 1976.

53. Janmahasatian S, Duffull SB, Ash S, Ward LC, Byrne NM, Green B. Quantification of lean bodyweight. Clin Pharmacokinet. 2005;44(10):1051-65.

54. Olutoye OA, Yu X, Govindan K, et al. The effect of obesity on the ED95 of propofol for loss of consciousness in children and adolescents. Anesth Analg. 2012;115(1):147-53.

55. Green B, McLeay SC. Anesthetizing the obese. Anesth Analg. 2011;113(1):1-3.

56. McLeay SC, Morrish GA, Kirkpatrick CM, Green B. Encouraging the move towards predictive population models for the obese using propofol as a motivating example. Pharm Res. 2009;26(7):1626-34.

57. Rigby-Jones AE, Sneyd JR. Pharmacokinetics and pharmacodynamics - is there anything new? Anaesthesia. 2012;67(1):5-11.

58. Cortinez LI, Anderson BJ, Penna A, et al. Influence of obesity on propofol pharmacokinetics: derivation of a pharmacokinetic model. Br J Anaesth. 2010;105(4):448-56.

59. Schuttler J, Stanski DR, White PF, et al. Pharmacodynamic modeling of the EEG effects of ketamine and its enantiomers in man. J Pharmacokinet Biopharm. 1987;15(3):241-53.

60. - Diepstraten J, Chidambaran V, Sadhasivam S, et al. Propofol clearance in morbidly obese children and adolescents: influence of age and body size. Clin Pharmacokinet 2012;51(8):543-51. The debate about the best scale descriptor for obese children given propofol continues. This current analysis favors TBW scaled using an allometric function. These results are similar to those reported in obese adults (Ref. [58]).

61. Mahmood I. Prediction of clearance and volume of distribution in the obese from normal weight subjects: an allometric approach. Clin Pharmacokinet. 2012;51(8):527-42.

62. McLeay SC, Morrish GA, Kirkpatrick CM, Green B. The relationship between drug clearance and body size: systematic review and meta-analysis of the literature published from 2000 to 2007. Clin Pharmacokinet. 2012;51(5):319-30.

63. Egan TD, Huizinga B, Gupta SK, et al. Remifentanil pharmacokinetics in obese versus lean patients. Anesthesiology. 1998;89(3): 562-73.

64. Rhodin MM, Anderson BJ, Peters AM, et al. Human renal function maturation: a quantitative description using weight and postmenstrual age. Pediatr Nephrol. 2009;24(1):67-76.
65. • Grassin-Delyle S, Buenestado A, Naline E, et al. Intranasal drug delivery: an efficient and non-invasive route for systemic administration: focus on opioids. Pharmacol Ther. 2012;134(3): 366-79. Intranasal drug delivery is gaining popularity. This review will outline the relevant aspects of the therapeutic interest and limits of intranasal delivery of drugs, with a special focus on opioids. The physiological characteristics of the nasal cavity as well as physicochemical properties (lipophilicity, molecular weight, ionisation) and pharmaceutical factors (absorption enhancers, devices for application) that should be considered for the development of nasal drugs are discussed.

66. Hadley G, Maconochie I, Jackson A. A survey of intranasal medication use in the paediatric emergency setting in England and Wales. Emerg Med J. 2010;27(7):553-4.

67. Kendall JM, Latter VS. Intranasal diamorphine as an alternative to intramuscular morphine: pharmacokinetic and pharmacodynamic aspects. Clin Pharmacokinet. 2003;42(6):501-13.

68. Kendall JM, Reeves BC, Latter VS. Multicentre randomised controlled trial of nasal diamorphine for analgesia in children and teenagers with clinical fractures. BMJ. 2001;322(7281): 261-5.

69. Kidd S, Brennan S, Stephen R, Minns R, Beattie T. Comparison of morphine concentration-time profiles following intravenous and intranasal diamorphine in children. Arch Dis Child. 2009; 94(12):974-8.

70. Borland M, Jacobs I, King B, O'Brien D. A randomized controlled trial comparing intranasal fentanyl to intravenous morphine for managing acute pain in children in the emergency department. Ann Emerg Med. 2007;49(3):335-40.

71. - Borland M, Milsom S, Esson A. Equivalency of two concentrations of fentanyl administered by the intranasal route for acute analgesia in children in a paediatric emergency department: a randomized controlled trial. Emerg Med Australas. 2011;23(2): 202-8. Intranasal fentanyl $(1.5 \mathrm{mcg} / \mathrm{kg})$ is an effective short term analgesic in the ED. The nasal cavity has limited volume and the authors suggest a concentrated formulation (150 mcg/ $m L)$ for best analgesia.

72. Furyk JS, Grabowski WJ, Black LH. Nebulized fentanyl versus intravenous morphine in children with suspected limb fractures in the emergency department: a randomized controlled trial. Emerg Med Australas. 2009;21(3):203-9.

73. Taylor DR, Gabrail N. Fentanyl pectin nasal spray for breakthrough cancer pain. Future Oncol. 2012;8(2):121-30.

74. • Hippard HK, Govindan K, Friedman EM, et al. Postoperative analgesic and behavioral effects of intranasal fentanyl, intravenous morphine, and intramuscular morphine in pediatric patients undergoing bilateral myringotomy and placement of ventilating tubes. Anesth Analg. 2012;115(2):356-63. Intranasal fentanyl was as effective as IV or IM morphine in controlling postoperative pain and emergence delirium. The authors suggest there may be a risk of laryngospasm if intranasal drugs pass through the posterior nasopharynx and irritate the vocal cords. This is yet to be investigated.

75. - Drover DR, Hammer GB, Anderson BJ. The pharmacokinetics of ketorolac after single postoperative intranasal administration in adolescent patients. Anesth Analg. 2012;114(6):1270-6. Numerous new devices with improved dose delivery accuracy or carrier mediums are appearing. The authors examined the PK of ketorolac in adolescents using one such device, showing it to be very effective. Allometric scaling was used to characterise clearance.

76. - De Oliveira GS Jr, Agarwal D, Benzon HT. Perioperative single dose ketorolac to prevent postoperative pain: a meta-analysis of randomized trials. Anesth Analg. 2012;114(2): 424-33. Ketorolac must be the most studied NSAID in anesthesia. This meta-analysis shows single dose systemic ketorolac 
is an effective adjunct in multimodal regimens to reduce postoperative pain and is accompanied by a reduction PONV. The $60 \mathrm{mg}$ dose offers significant benefits but there is a lack of current evidence that the $30 \mathrm{mg}$ dose offers significant benefits on postoperative pain outcomes in adults.

77. Larsson P, Eksborg S, Lonnqvist PA. Onset time for pharmacologic premedication with clonidine as a nasal aerosol: a double-blind, placebo-controlled, randomized trial. Pediatr Anesth. 2012;22(9):877-83.

78. Larsson P, Nordlinder A, Bergendahl HT, et al. Oral bioavailability of clonidine in children. Pediatr Anesth. 2011;21(3): 335-40.

79. • Brunette KE, Anderson BJ, Thomas J, Wiesner L, Herd DW, Schulein S. Exploring the pharmacokinetics of oral ketamine in children undergoing burns procedures. Pediatr Anesth. 2011; 21(6):653-62. Management of children presenting for burns treatments can be distressing for staff and children. Administration of oral ketamine before interventions gains analgesia through both parent and metabolite effects.

80. Ong CK, Seymour RA, Lirk P, Merry AF. Combining paracetamol (acetaminophen) with nonsteroidal antiinflammatory drugs: a qualitative systematic review of analgesic efficacy for acute postoperative pain. Anesth Analg. 2010;110(4):1170-9.

81. Mehlisch DR, Aspley S, Daniels SE, Southerden KA, Christensen KS. A single-tablet fixed-dose combination of racemic ibuprofen/ paracetamol in the management of moderate to severe postoperative dental pain in adult and adolescent patients: a multicenter, two-stage, randomized, double-blind, parallel-group, placebocontrolled, factorial study. Clin Ther. 2010;32(6):1033-49.

82. - Hannam J, Anderson BJ. Explaining the acetaminophen-ibuprofen analgesic interaction using a response surface model. Paediatr Anaesth. 2011;21(12):1234-40. Literature concerning analgesia after different ibuprofen-acetaminophen drug combinations is conflicting. The authors use a drug surface response relationship to explain these conflicting results.

83. Hannam J, Anderson BJ, Veyckemans F. Tears at breakfast. Pediatr Anesth. 2012;22(4):419.

84. Corcos L, Lagadic-Gossmann D. Gene induction by phenobarbital: an update on an old question that receives key novel answers. Pharmacol Toxicol. 2001;89(3):113-22.

85. Eker HE, Yalcin Cok O, Aribogan A, Arslan G. Children on phenobarbital monotherapy requires more sedatives during MRI. Pediatric Anesthesia. 2011;21(10):998-1002.

86. Sumpter A, Anderson BJ. Phenobarbital and some anesthesia implications. Pediatr Anesth. 2011;21:995-7.

87. - Aouad MT, Yazbeck-Karam VG, Mallat CE, Esso JJ, SiddikSayyid SM, Kaddoum RN. The effect of adjuvant drugs on the quality of tracheal intubation without muscle relaxants in children: a systematic review of randomized trials. Pediatr Anesth. 2012;22(7):616-26. Neuromuscular blocking drugs are often omitted during intubation. Unfortunately, the literature abounds with alternative drug combinations. The authors conclude that propofol may be the adjuvant of choice for a rapid sevoflurane induction. The only adjuvant identified in propofol induction was remifentanil (4 $\mathrm{mcg} / \mathrm{kg}$ ).

88. Tsuruta S, Satsumae T, Mizutani T, et al. Minimum alveolar concentrations of sevoflurane for maintaining bispectral index below 50 in children. Pediatr Anesth. 2011;21(11):1124-7.

89. Bourgeois E, Sabourdin N, Louvet N, Donette FX, Guye ML, Constant I. Minimal alveolar concentration of sevoflurane inhibiting the reflex pupillary dilatation after noxious stimulation in children and young adults. Br J Anaesth. 2012;108(4):648-54.

90. Klockars JG, Hiller A, Munte S, van Gils MJ, Taivainen T. Spectral entropy as a measure of hypnosis and hypnotic drug effect of total intravenous anesthesia in children during slow induction and maintenance. Anesthesiology. 2012;116(2):340-51.

91. Kraemer FW, Stricker PA, Gurnaney HG, et al. Bradycardia during induction of anesthesia with sevoflurane in children with Down syndrome. Anesth Analg. 2010;111(5):1259-63.

92. - Ince I, de Wildt SN, Peeters MY, et al. Critical illness is a major determinant of midazolam clearance in children aged 1 month to 17 years. Ther Drug Monit. 2012;34(4):381-9. This paper supports the notion of reduced clearance of many drugs during severe illness. Midazolam is metabolized by CYP3A4/5, an enzyme responsible for many other drugs as well. Critical illness seems to be a major determinant of midazolam clearance in children of all ages. This may result from reduced CYP3A4/5 activity due to inflammation.

93. Rabbitts JA, Groenewald CB, Dietz NM, Morales C, Rasanen J. Perioperative opioid requirements are decreased in hypoxic children living at altitude. Pediatr Anesth. 2010;20(12): 1078-83.

94. - Rabbitts JA, Groenewald CB, Rasanen J. Geographic differences in perioperative opioid administration in children. Pediatr Anesth. 2012;22(7):676-81. Practitioners working in different countries comment on differing opioid requirements among nationalities. This study quantifies those differences. Children in Central and South America received less opioid intraoperatively than African and Indian children, under standardized anesthesia for cleft surgeries. Reasons remain unknown.

95. - Jimenez N, Anderson GD, Shen DD, et al. Is ethnicity associated with morphine's side effects in children? Morphine pharmacokinetics, analgesic response, and side effects in children having tonsillectomy. Pediatr Anesth. 2012;22(7):669-75. Ethnicity appears associated with these differences in effect from opioids. Pruritus was four times and emesis seven times more frequent in Latino compared with non-Latino children from a North American hospital. Neither PK differences nor polymorphisms could explain these differences. Further investigation is required so that we can better tailor drug therapy.

96. Stewart DW, Ragg PG, Sheppard S, Chalkiadis GA. The severity and duration of postoperative pain and analgesia requirements in children after tonsillectomy, orchidopexy, or inguinal hernia repair. Pediatr Anesth. 2012;22(2):136-43.

97. Tomecka MJ, Bortsov AV, Miller NR, et al. Substantial postoperative pain is common among children undergoing laparoscopic appendectomy. Pediatr Anesth. 2012;22(2):130-5.

98. Makkar JK, Singh NP. Absence of perioperative analgesia in children with cerebral palsy: how justified is it? Pediatr Anesth. 2012;22(2): 178 .

99. - Walker SM. Perioperative care of neonates with Down's syndrome: should it be different? Br J Anaesth. 2012;108(2): 177-9. Some assume that handicapped children have reduced need for postoperative analgesia. This editorial looks at the evidence and suggest that such biases have little weight behind them for children with Trisomy 21 (or indeed cerebral palsy; Ref. [98]).

100. • Cheeseman JF, Winnebeck EC, Millar CD, et al. General anesthesia alters time perception by phase shifting the circadian clock. Proc Natl Acad Sci USA. 2012;109(18):7061-6. This paper is slightly off center-field. Nevertheless, it may explain some of the disorientation and sleep disturbance observed in children after prolonged anesthesia. The circadian clock in the honey bee is genetically similar to that in humans. Isoflurane anesthesia creates a phase lag, evident in both the mRNA turnover within the central clock and in disturbed behavioral rhythms. The inhalation agent creates jet lag. 